\title{
Advance Pricing of Services and Other Implications of Separating Purchase and Consumption
}

\author{
Steven M. Shugan \\ Jinhong Xie \\ University of Florida, Gainesville
}

It is important to differentiate between the act of purchasing and the act of consuming. Understanding this separation provides many implications and areas for future research. For example, the separation creates buyer uncertainty about the utility from consumption. Consider buying a ticket for a concert in advance. Here, buyers may be uncertain about their future state (e.g., health, expected conflicts, mood) at the time of the concert. This article explores the desirability and implications of this separation and the creation of it (which is often a consequence of the service provider's selling strategy). The authors show that service providers can improve profits by advance ticketing, perhaps, to the level of first-degree price discrimination (although usually there is no loss in aggregate consumer surplus). These profits are possible despite a service provider's inability to price discriminate.

We should differentiate between the act of purchasing and the act of consuming. When purchasing manufactured goods or services, we often implicitly assume that buyers receive utility at the time of purchase. Although utilities do drive choices (e.g., Hauser and Urban 1979, Hauser and Wernerfelt 1990), the utility from consumption may occur in the distant future.
Assuming immediate consumption overlooks a rich aspect of behavior. In reality, buyers often inventory manufactured products for future consumption. Moreover, buyers often purchase services well before the time of consumption. Travel agents, for example, may sell vacationers vouchers for shuttle services from the airport to the hotel well in advance of the trip. Advance purchasing is quite common in many incustries including travel, entertainment, and personal services (Shugan and Xie 1997). Buyers can advance purchase tickets, stamps, tokens, personal vouchers, passes, $\alpha$ other certifications good for consumption during a specified period from tour operators, sporting events organizers, and so on.

Although purchase and consumption already occur at different times, past technological constraints limited its domain. Were amusement parks to advance sell discounted entry tickets, for example, arbitrage would be possible. Scalpers could buy discounted tickets to resell them at higher prices at a future date. This ticket scalping limited a firm's ability to advance sell at a discount while selling full price at the gate.

Technological advanoes, however, are making arbitrage more difficult. Smart tickets or cards, now used by Disney, securely embed information on a magnetic strip. The black market for tickets disappears because buyers are unable to read the magnetic strips and verify a ticket's

The authors are listed in alphabetical order for lexicographic convenience; both authors contribured equally to the article. We would like to thank members of the workshops at the University of Florida, Washington University, and IFORMS Meetings in Syracuse for their many helpful comments. We give special thanks to Richard Lutz, Barton Weitz, David Sappington, Tracey Lewis, and Richard Ramano. We also thank Russ Berrie for his financial support. 
value. Smart tickets prevent buyers from, for example, identifying expired tickets, reading expiration dates, or learning of restrictions on admission (Shugan and Xie 1999). Smart cards also allow highly complex advance purchases that transaction costs would otherwise prohibit. For example, a buyer could advance purchase from a restaurant a series of packaged dinners that are only valid for specified nights during specified time intervals. Smart cards allow the restaurant to advance sell to specific customers with the ease of merely pressing a few buttons. Although these tickets may have visible information, the magnetic strip would hide the past use of the ticket and the remaining value.

Moreover, Internet transactions via Web sites also can lower the cost of purchasing in advance of consumption. Without physically visiting a movie theater, consumers could electronically visit the theater's Web site and advance purchase movie tickets or customized packages (e.g., dinner, movie, popcorn, and parking), which include both advance sales and bundling. Although we do not analyze bundling strategies, technology advances also allow advance sale of bundles. Amusement parks that now sell standardized tickets could use smart cards to presell packages including customized attractions, shows, meals, merchandise, and lodging.

This article explores the marketing implications of separating purchase and consumption with an emphasis on advance selling. For example, we show that the advance period is a better time to sell services. Consequently, advance selling can substantially increase the profits of service providers.

\section{SEPARATING PURCHASE AND CONSUMPTION}

When buyers purchase services for future consumption, they can be uncertain about their valuations for the service at the time of consumption. Hence, consumerexpected utilities at purchase could differ from the actual utility from future consumption. We view these differences as resulting from an uncertain consumption state (e.g., Bucklin, Gupta, and Siddarth 1998; Guadagni and Little 1983; Kreps 1979; Wernerfelt 1995). This section further develops this idea and relates it to the literature on state-dependent utility theory.

With uncertainty about future valuations, buyer utilities can vary with the state of nature. For example, the benefit from an American Automobile Association membership may depend on whether the driver gets a flat. State dependent utility functions (e.g., see Cook and Graham 1977; Fishburn 1974) and their extensions (e.g., Plummer and Hartman 1986) have applications in areas such as public policy and risk assessment. Note that this literature differs from the vast literature on random utility models. The latter assumes that buyers know utilities with certainty but that the researcher is unable to explain choice behavior precisely because of potential observational deficiencies (Ben-Akiva and Lerman 1985; McFadden 1973).

This article goes beyond state-dependent utility. For example, we examine the direct implications of selling to a buyer at different points in time. Consistent with the statedependent utility literature, we allow a buyer's valuation for a service to depend on buyer states at the time of consumption. Consider, for example, someone who advance purchases a cruise. At the time of the cruise, the buyer's valuation for the cruise depends on the buyer's state including the buyer's health, the buyer's mood, unforeseen alternatives, scheduling conflicts, the state of companions, personal factors, and so or. In general, when buyers make a purchase, this uncertainty must play a role.

We argue that buyers consider their uncertainty about furure consumption states at the time of purchase. They anticipate future states when they may consume the manufactured product or service. Consider the purchase of a dry-cleaning service. At the time of purchase, buyers must anticipate the future consumption state and the corresponding utility from that future consumption state. The maximum price the buyer would be willing to pay at purchase, therefore, depends on the expected utility from the expected consumption state. The greater the expected utility at the time of purchase, the more the buyer is willing to pay at the time of purchase, that is, the greater the buyer's reservation price. The buyer, for example, would pay more when he or she expects to attend a special occasion for which having professionally pressed clothing is invaluable. Here, the buyer will have a higher valuation (i.e., higher reservation price) for the cleaning. If the buyer expects that the clothing will hang in a çloset for an extended period, perhaps until pressing is again required, the buyer's valuation price is smaller.

For most services, many future consumption states are possible. Faced with not knowing the future state, we model buyers as weighing the valuations associated with each consumption state by each state's respective likelihood. The resulting valuation represents the buyer's expectation regarding the utility of the service. It is this expectation that should replace the usual valuation or utility used by models of buyer purchasing. Rather than buying based on the utility enjoyed from consumption of the service, purchases depend on the expected utility in the consumption period.

For example, when purchasing a vacation package, buyers may consider the likelihood of many different consumption states (e.g., being healthy, being in the mood for a vacation, and having no significant conflicts). Buyers place greater weights on more likely states and smaller weights on less likely states. 
Although previous examples emphasized the similarity of manufactured products and services, the timing of service consumption sometimes differs. Buyers often inventory manufactured products for consumption in specific states. For example, buyers can inventory soft drinks until they are thirsty. With services, however, buyers are often less able to control the timing of consumption. Service providers, for example, can set fixed times when the services are offered and fixed times when they are sold. For example, many services have limited hours of operation. Here, buyers making advance ticket purchases for services often yield less control and more uncertainty about their future consumption states.

Note that in addition to consumption state uncertainty, buyers may also have uncertainty about service attributes. A traveler who purchases an umbrella, for example, may be uncertain about whether it will rain (i.e., the consumption state) as well as how the umbrella will perform in the rain (i.e., the product attributes). The former uncertainty continues across time, whereas the latter uncertainty becomes resolved with repeated use. This aricle emphasizes consumption state uncertainty, which, as shown, has important implications for marketing practice as well as understanding market behavior. See Roberts and Lattin (1991) for a discussion of uncertain product attributes.

Finally, note that we assume that future consumption states are unknown. However, some interesting research suggests that consumers may manipulate their own states (Gibbs 1993). This research has potentially important implications for separating purchasing and consumption.

\section{IMPLICATIONS FOR MARKETING}

We noted that the separation of purchase and consumption makes buyers uncertain about their future valuations (i.e., willingness to pay). Seller uncertainty may also exist. In this section, we present some possible implications of buyer and seiler uncertainty induced by the separation of purchase and consumption. After presenting these ideas, we continue to develop more fully one of these ideas, that is, advance selling.

\section{Uncertainty in Seller Costs}

The separation may make sellers uncertain about their future costs. For example, a health maintenance organization sells services to members before knowing future costs, that is, whether these members will be in future healthy or unhealthy states. Obvious examples include life or health insurance companies whose payments depend on future customer states. Other examples include services such as restaurants with buffets, whose costs depend on the hunger of their customers, and car rental companies, whose costs depend on the number of miles driven. These examples suggest (a) the introduction of more complex use-based pricing, (b) targeting only low-cost customers, and (c) restrictions on use. Although contingent claims research (e.g., Brennan 1979) discusses somewhat related topics, this area remains attractive for future research.

\section{Changes in the Quantity Purchased}

The separation of purchase and consumption may cause customers to purchase in different quantities. In their seminal article, Blattberg, Eppen, and Lieberman (1981) suggest that buyer uncertainty about future prices causes buyers to inventory non-durables, making price deals profitable. Subsequent research suggests promotional programs can shift purchase decisions across time, thereby changing the time between purchase and consumption. Indeed, all studies of buyer inventorying behavior are studying one implication of deferred consumption. Future research might suggest how service providers could participate by selling options to buy future services at guaranteed prices. Png (1989), for example, suggests that reservations play that role.

\section{Buyer Demand for Flexibility}

Separating purchase and consumption may cause buyers to react to uncertainty by creating a demand for flexibility or assortments useful in multiple consumption states. Buyers who are uncertain about future states, for example, may desire a leisure service with an assortment of cuisines, entertainment options, and available merchandise.

A desire for flexibility may encourage sequential or hierarchical decision making (e.g., see Bettman 1970). Buyers may purchase an assortment of manufactured products to ensure future flexibility (e.g., see Kahn and Lehmann 1991). Future research might suggest how service providers could offer a menu of tickets varying in both flexibility and price (e.g., 3-day admission, six rides per day, valid 6:00 p.m. to 8:00 p.m.).

\section{Tickets Customized to the Time of Purchase}

It follows that buyer uncertainty increases with time. For example, a longer duration of time between purchase and consumption may increase buyer uncertainty, ceteris paribus. Consider buyers who purchase tickets for an outside concert. When purchasing minutes before the concert, relatively little uncertainty exists about the consumption state. When buyers purchase tickets 1 week in advance, in contrast, buyers may be more uncertain. Still more buyer uncertainty exists when buyers purchase tickets a month in 
advance. This uncertainty may include factors such as unforeseen obligations, the buyers' reaction to congestion at the concert, the buyers' health (e.g., headaches, colds, hunger), the state of companions, and unforeseen opportunities at the time of the concert. When buying some products and services, uncertainty about network externalities may be important (Padmanabhan, Rajiv, and Srinivasan 1997; Xie and Sirbu 1995).

Future research could explore how service providers might vary the flexibility, price, assortment, and quantities associated with advance tickets, depending on the duration of time between the ticket sale and the specified time of consumption. Perhaps it is possible to sequentially offer different service packages over time analogous to the optimal launch strategies suggested by Moorthy and Png (1992) in which a firm sequentially serves high- and lowvaluation buyers.

\section{The Relative Advantage of Buyers and Sellers}

The separation of purchase and consumption may create a dynamic asymmetry between the buyer and seller. The relative uncertainty buyers and sellers have about buyer consumption states changes as the time of consumption approaches. Often, as consumption approaches, the buyer gains more information than the seller does about the buyer's consumption state. As we move further from the consumption period, both the buyer and seller have high degrees of uncertainty. In many cases, they have equal levels of uncertainty about unpredictable events, such as the buyer's future mood at the time of consumption, unforeseen opportunities of alternate consumption, and the weather at the time of consumption. In other cases, sellers know far more than buyers do. Sellers, for example, may have experience with many previous buyers as well as many previous consumption situations. Based on past experience, sellers could know much more about what to expect than buyers do. Health insurers, for example, can better predict the future state of clients using past data including demographic and occupational information. As time progresses, however, the customer may become more aware of personal symptoms and their own individual health Soon, insured customers have better knowledge about their consumption state and their utility for insurance than the insurance company. For this reason, insurance companies may refuse to cover preexisting medical conditions. Given healthy consumption states, however, insured customers may never consume the benefits of the health insurance policy. Hence, purchase decisions well before consumption often favor sellers (a situation enhanced by differences in risk aversion) because sellers may be better able to predict consumption states using past experience from many previous customers. Purchase deci- sions close to the time of consumption, in contrast, will often favor buyers. Future research might empirically examine the impact on buyer behavior.

\section{The Opportunity for Price Discrimination}

In some markets, earlier buyers are more price sensitive than buyers who purchase closer to the time of consumption. The separation of purchase and consumption creates the opportunity to price discriminate over time when arrival is correlated with price sensitivity and arbitrage is costly. This situation occurs in the travel industry in which leisure travelers often pay less than business travelers do. However, as Desiraju and Shugan (1998) note, this practice improves profits because business travelers have expense accounts. Hence, it may not be as applicable to other industries. Related research in several literatures also considers price discrimination of this type (e.g., Gale and Holmes 1993; Lewis and Sappington 1994; and Dana 1998). Yield management techniques provide computational methods for achieving this goal (Desiraju and Shugan 1998; Metters and Vargas 1999). Perhaps temporal discrimination is possible for nonprice variables.

\section{Restricting the Consumption Period Increases Buyer Uncertainty}

The separation between purchase and consumption creates more buyer uncertainty, ceteris paribus, when buyers are unable to control when consumption occurs (e.g., a Saturday afternoon football game). When buyers control or influence the timing of consumption, buyers can wait to consume until a particular state occurs. When buyers inventory a soft drink, for example, they can consume only when they are thirsty.

Tickets often have lifetimes or prespecified periods when the ticket is valid. With a longer lifetime, it is more likely that a favorable consumption state will occur in the lifetime. Hence, buyers are confident that they have the ability to synchronize the consumption to occur in a favorable state. This situation occurs with open-ended tickets with no expiration date.

Sellers sometimes have an ability to influence a ticket's lifetime. Shorter lifetimes create more uncertainty, which lowers buyer valuations but gives sellers a greater relative advantage. Longer lifetimes create less uncertainty, which raises buyer valuations but gives sellers a relative disadvantage because sellers remain uncertain about the realized valuations of buyers. With less uncertainty, buyers know their valuations (i.e., what they are willing to pay) better than sellers. More uncertainty does the opposite.

Sellers' ability to influence a ticket's lifetime may affect the marketing strategies adopted by an industry. Sometimes, buyers control when consumption occurs 
(e.g., purchasing beverages from vending machines). Other times, consumption periods can be limited (e.g., live sporting events, live concerts, scheduled events, and natural phenomena). As the buyer loses control over the timing of consumption, the amount of uncertainty about the expected valuation, ceteris paribus, increases. No literature currently exists on this topic.

\section{Advance Pricing Can Be Profitable Even With Homogeneous Buyers (i.e., without price discrimination)}

Another implication of separation concerns advance pricing or forward selling at the expected valuation price. The following sections explore in detail how advance pricing improves seller profits. The improvement occurs when buyer valuations are sufficiently large compared with the service provider's variable cost.

The seller inability to inventory many services provides the opportunity for the service pitovider to exploit buyer uncertainty about future valuations.

\section{ADVANCE SELLING AND PRICING}

Advance selling is found in the service sector. It could result from the special properties of many services (e.g., Rust and Oliver 1994; Shugan 1994). An airplane, for example, departs on a specific date at a specific time. The same is true for sporting events, music concerts, trains, county fairs, Broadway plays, buses, circuses, county fairs, rodeos, cruises, and many other services. In each case, the customer of the service must be physically present at the service at a specific time, and advance selling at a different advance price becomes possible.

Services adopt different practices concerning advance selling. Some offer it, whereas others do not. Some services offer advance sales but at the same advance price as the spot price. Repair services and public utilities usually offer no advance sales. Delivery services, airlines, and some entertainment services offer different spot and advance prices. Other services offer only advance ticketing (e.g., Las Vegas shows).

Sometimes, technological limitations prevent service providers from advance selling. Restaurants and car washes might find advance selling administratively difficult because of problems including accounting for tickets, physically creating complex tickets, arbitrage of tickets, administering advance-pricing programs across different locations, and allowing buyers to prepurchase without the inconvenience of trekking to the service. Smart cards and inexpensive small computer software are changing this situation because smart cards store all information encrypted on the card itself. Soon, a restaurant could presell a series of dinners including specific times for a specific time interval excluding prespecified blackout periods. Moreover, smart cards allow customization to individual customer wants.

We conclude that advance selling at a different advance price may soon be possible for most service providers. However, we must understand the conditions under which advance selling improves profits.

We know that advance selling increases the time between purchase and consumption. Therefore, it increases buyer uncertainty about buyer valuations because of consumption state uncertainty. That increase in buyer uncertainty usually favors sellers, because buyers, unlike sellers, become more certain about their valuations as the time of consumption approaches. Consider the organizers of an outdoor county fair and a prospective attendee. The fair will be held at a fixed date and time. The consumption state, for this example, is the state of the attendee, any companions, spouses, and children on the fair date. It will also depend on unexpected events (e.g., visits by relatives, projects at work). On the fair date, for example, the prospective attendee may be energetic, well rested, have a desire for an active environment with other people, and have a desire to be outside. Then, the attendee prefers the fair to competing alternatives at a relatively high price (i.e., valuation). On the fair date, in contrast, the state of the attendee may include having a headache, being too tired to walk, feeling the weather is inclement, having travel difficulties such as car problems, and so on. Here, the consumption state creates a relatively low valuation for the fair.

Hence, on the fair date, buyers know their consumption state. Weeks before, however, they are uncertain about these states. Sellers, in contrast, are less knowledgeable about buyer valuations on the fair date. Sellers are at a relative disadvantage when bargaining price. On the fair date, sellers can either offer a relatively high price causing only buyers in favorable states to buy or offer a relatively low price causing all buyers to buy, but sellers forgo significant profits from buyers in favotable states who would have paid much more. Weeks in advance of the fair, in contrast, sellers are in a better negotiating position because, like sellers, buyers are uncertain about their future consumption state. This uncertainty allows the buyer to charge a higher price, based on the expected consumption state, and to sell to all potential buyers.

For example, suppose there are 100 potential ticket buyers with the same expected valuations. When in a favorable consumption state, they will pay $\$ 5$ for a spot ticket, that is, at the gate on the fair date. When in unfavorable states, they will pay $\$ 2$. Suppose the states are equally likely. When the fair offers only spot tickets, the fair can sell tickets either at $\$ 2$, selling to all buyers, or at $\$ 5$, selling only to half of the buyers, that is, only buyers in favor- 
able consumption states. The former option yields profits of $\$ 2 \times 100=\$ 200$, whereas the latter option yields expected profits of $\$ 5 \times 100 \times 1 / 2=250$. The latter option is more profitable. So, the optimal spot-pricing strategy is to spot price tickets at $\$ 5$ at the gate, sell to buyers in favorable consumption states (i.e., half the potential buyers), and earn an optimal profit of $\$ 250$.

Now consider advance selling. Weeks before the fair date, the two consumption states were equally likely. The expected valuation or reservation price for a buyer, say several weeks before the fair, is the expected value of the tickets, that is, $(\$ 5+\$ 2) / 2$ or $\$ 3.50$ for tickets. When the fair offers advance tickets, the fair sells to all potential buyers at $\$ 3.50$ and earns profits of $\$ 3.50 \times 100=\$ 350$. Hence, the fair earns additional profits of $\$ 350-\$ 250$ or $\$ 100$ by offering advance selling. The fair improves profits by $\$ 100 / \$ 250$ or $40 \%$ with advance selling. Advance selling can double profits (Shugan and Xie 1997) given the right parameters.

Note that the fair does no better with first-degree discrimination. Suppose at the gate, the fair could identify whether each buyer was in a favorable or unfavorable state and charge each buyer accordingly. Then, at the gate, half the ticket buyers would be in favorable states, and the fair would charge them $\$ 5$. The other half would be in unfavorable states, and the fair would charge them $\$ 2$. The fair's profits would be $\$ 5$ on 50 customers and $\$ 2$ on the remaining 50 customers. Profits would be $\$ 350$. These profits equal the profits enjoyed with advance selling.

This example was somewhat specific but demonstrated the advantage of advance selling. We now provide more general conditions when advance selling improves profits.

\section{CONDITIONS FOR THE SUPERIORITY OF ADVANCE PRICING}

\section{Analysis of Homogeneous Markets}

This section shows that even with homogeneous markets with no opportunity for price discrimination, advance selling offers service providers greater profits. With heterogeneity, advance selling also allows segmentation. To illustrate the general principle, we begin with a simple model.

Although infinite states are possible, for simplicity, consider two possible states at the time of consumption: favorable or unfavorable. In favorable states, buyers will have a valuation or reservation price of $p_{F}$ for consumption. In unfavorable states, buyers have reservation prices of $p_{v}$. Hence, buyers will pay either $E R P$ or $p_{v}$ for a spot ticket, depending on their state at the time of consumption. Although buyers are uncertain about which consumption state will occur, they expect the favorable state will occur with probability $q$. Hence, buyers will pay the expected reservation price of $E R P=q p_{F}+(1-q) p_{v}$ for the advance tickets. Finally, when we sell both spot and advance tickets, buyers will choose the ticket that maximizes their surplus (i.e., the valuation minus the actual price).

As the service provider, we have a small marginal cost of $C<p_{U}$ associated with each incremental sale. We know $p_{F}, p_{v}$, and $q$. However, we are unable to price discriminate between potential buyers at the gate, that is, at the time of consumption, possibly because either (a) we are unable to determine the potential attendee's consumption state or (b) we find it costly to administer a negotiated price at the gate.

Given the buyer's decision to maximize surplus, there are only five possible strategies to consider (see Shugan and Xie 1997 for details):

1. offer only advance tickets at $E R P$,

2. offer a spot price of $p_{U}$,

3. offer a spot price of $p_{p}$

4. offer an advance price of $E R P$ and a spot price of $p_{u}$, or

5. offer an advance price of $E R P$ and a spot price of $p_{F}$.

We assume that service providers announce their strategies in the advance period. We also assume that the firm honors announced prices and does not announce one price and then charge another. We further discuss this issue later.

Note that, in this case, all consumers have the same $E R P$ in the advance period (i.e., are homogeneous), but in the consumption period, some buyers have a valuation of $p_{F}$ whereas others have a valuation of $p_{v}$ This formulation yields the following theorem and the following two lemmata. Proofs are in the appendix.

Theorem 1: When all buyers are homogeneous in the advance purchase period (but not in the consumption period), the service provider maximizes profits by offering only advance tickets priced at the $E R P$, provided that the buyer's reservation price in an unfavorable state still exceeds the service provider's unit cost.

Let $M$ be the number of buyers in the market. Lemmata 1 and 2 follow.

Lemma 1: Compared with a high spot price $p_{p}$ offering advance tickets at $E R P$ improves profits by $(1-q)$ $\left(p_{u}-C\right) M$.

Lemma 2: Compared with a low spot price $p_{\psi}$, offering advance tickets at $E R P$ improves profits by $q\left(p_{F}-p_{v}\right) M$.

Theorem 1 reveals that, when prospective attendees are homogeneous in the advance purchase period (but not the consumption period), we make more profits by offering advance tickets at the ERP price than at any spot-pricing 
strategy. The additional profits come from getting all prospective attendees to buy at the advance ticket price. That advance price is higher than the highest spot price that ensures that all attendees buy, that is, $p_{v}$. The additional profits come from transacting with customers when customers are uncertain about their future consumption state. At the time of consumption, the service provider is unable to obtain a price greater than $p_{v}$ from customers in an unfavorable consumption state.

Lemma 1 reveals that compared to the high spot price, the advance price provides greater profits, and those greater profits are a function of the difference between $p_{U}$ and $C$. Remember that advance pricing allows us to sell to these customers at a price greater than $p_{U}$, that is, ERP. The difference, $p_{U}-C$, represents the advantage of selling tickets to buyers who will subsequently be in an unfavorable consumption state. Note that as this difference decreases, the advantage of capturing these customers decreases. When C exceeds $p_{v}$, our costs exceed the buyer's reservation price in an unfavorable state. Consequently, there is no advantage from an advance purchase ticket, and the high spot price generates greater profits.

Lemma 1 also reveals that the advantage of advance selling over a high spot price decreases as $q$ increases, because as $q$ increases, favorable consumption states are more likely, and the advance price of $E R P$ approaches $p_{F}$ When $q$ equals 1 , for example, consumption states are certainly favorable, and the advance price equals $p_{F}$

Lemma 2 reveals that compared to the low spot price, advance selling provides greater profits, and those greater profits are a function of the difference between $p_{F}$ and $p_{l^{\prime}}$. This difference represents the difference in the customer's reservation price in the different states. As the difference in utility between the two consumption states increases, the difference between the ERP and $p_{U}$ increases. Hence, as the difference in these states increases, we enjoy more profits at the advance price of $E R P$ than at the spot price of $p_{u}$. Finally, Lemma 2 also reveals that as $q$ increases, buyers will pay more for the advance purchase ticket, so the relative profitability of that ticket increases over a spot ticket of $p_{v}$

So far, we have not discussed combination strategies with both advance selling followed by spot selling. With homogeneous markets, these strategies offer no advantage. Offering both advance tickets at $E R P$ and spot tickets at the low reservation price $p_{U}$ is equivalent to offering only spot prices, because all buyers would wait and buy the spot ticket. Hence, the only viable combination strategy would be to offer the advance ticket at $E R P$ and the spot ticket at the higher reservation price $p_{P}$ Consider this latter strategy. With homogeneous customers in the advance purchase period, all customers would buy the advance purchase ticket at $E R P$, and no customers would be left to purchase the spot ticket at $p_{P}$ Hence, unless buyers are het-
TABLE 1

Market Prices and Profits (homogeneous case)

\begin{tabular}{lccc}
\hline & $\begin{array}{c}\text { Advance Ticket } \\
\text { Only or Combination }\end{array}$ & $\begin{array}{c}\text { Spot High } \\
\text { Price Only }\end{array}$ & $\begin{array}{c}\text { Low Price } \\
\text { Spot Only }\end{array}$ \\
\hline Price & $E R P=q p_{F}+(1-q) p_{U}$ & $p_{F}$ & $p_{U}$ \\
Profit & $\Pi_{A}=(E R P-C) M$ & $\Pi_{H}=q\left(p_{F}-C\right) M$ & $\Pi_{L}=\left(p_{U}-C\right) M$ \\
$\begin{array}{l}\text { Lost profit } \\
\text { compared } \\
\text { to advance } \\
\text { selling }\end{array}$ & 0 & $(1-q)\left(p_{U}-C\right) M$ & $q\left(p_{F}-p_{U}\right) M$ \\
\hline
\end{tabular}

erogeneous, combination strategies offer no greater profits than offering only advance purchase tickets.

Table 1 summarizes our results for the homogeneous market in the advance purchase period. We see that advance ticketing provides the greatest profits provided that the low spot price of $p_{U}$ is still profitable, that is, greater than $C$.

\section{Homogeneous Markets: Comparing Advance Pricing With First-Degree Price Discrimination}

In this section, we compare the profits of advance pricing with the profits from first-degree price discrimination. With a first-degree price discrimination strategy, we would offer a high spot price of $p_{F}$ to customers in a favorable consumption state and $p_{U}$ to customers in an unfavorable consumption state. Of course, this strategy may be very difficult or impossible to implement. Nevertheless, first-degree discrimination provides an important benchmark for an advance-ticket strategy.

Implementing a first-degree price discrimination strategy provides a profit of $\left(p_{F}-C\right)$ for a fraction of $q$ of the customers and $\left(p_{U}-C\right)$ for a fraction of $(1-q)$ of the customers. It follows that total profits are precisely equal to $E R P-C$. Hence, offering the advance purchase ticket yields the same profits as first-degree price discrimination at the gate. Selling to customers in advance, before they know their consumption state, allows the service provider to extract each customer's entire surplus. Advance pricing is better than selling at any spot price alone and yields the same profits as selling to customers based on unobserved consumption states at the gate.

\section{Multiple Consumption States: The Uniform Distribution Case}

For simplicity, our previous discussion allowed only two possible consumption states. Multiple consumption 
states, however, are possible. Theorem 2 presents a sufficient, but not necessary, condition for the superiority of advance selling with multiple consumption states.

Theorem 2: When the future valuations (or reservation prices) of consumers for a service are uniformly distributed between $a$ and $b, b>a$, advance pricing provides greater profits than spot-pricing alone, when marginal costs $C$ are sufficiently low, $C<a$.

Hence, multiple consumption states do not alter our earlier results.

\section{An Example of a Heterogeneous Market:}

The last sections explored the situation in which all buyers had the same likelihood of a favorable consumption state. This section explores a more general situation. Consider, for example, a car rental company located at an airport. The rental company offers two possible refueling options. The first option is for the car renter to advance purchase a full tank of fuel. The second option is to return the gas tank full and pay a high spot price for any missing fuel. This type of option has become common among car rental companies.

When deciding whether to advance purchase the fuel, the car renter is uncertain about the consumption state when the car is returned. The renter can envision two possible outcomes. First, the car renter may find a convenient gas station en route to the airport and find the refueling effortless. Here, the utility of an advance purchase full tank of gas is low. Second, the car renter may arrive late at the airport, be unable to find a convenient gas station, risk missing a flight in an effort to find a gas station, and pay a high spot price. In this outcome, the utility of an advance purchased full tank of gas is high.

Suppose there are two buyer segments. The first segment is relatively disposed toward easily finding a gas station. This segment may be renters who travel often. They have flexible schedules, have sufficient time en route, and are comfortable reading a map. In short, these renters are more likely to find a gas station with ease. For this example, let this segment have a $90 \%$ chance of finding a gas station.

The second segment is relatively disposed toward a state of buying at spot. They are renters who have a lower chance of finding a gas station before their plane departs. They are renters who are unfamiliar with the city, are on a very tight schedule, often get lost, and have trouble managing their time. Let this segment have a $60 \%$ chance of finding a gas station.

In this example, assume the spot fuel price charged by the car rental company is set to a legal maximum of $\$ 50$ per tank. We recognize that a complete analysis requires this number to be endogenous. For this example, however, assume it is $\$ 50$. The price for gasoline at city gas stations is $\$ 10$ per tank. Suppose each segment uses one tank of gasoline.

Members of the first segment expect to pay $(.9 \times \$ 10)+$ $(.1 \times \$ 50)=\$ 14$ if they do not advance purchase a tank of gas. Members of the second segment expect to pay $(.6 \times \$ 10)$ $+(.4 \times \$ 50)=\$ 26$ if they do not advance purchase. Hence, were the car rental company to announce an advance price of $\$ 25$, for example, the first segment waits and the second segment advance purchases.

For simplicity, assume each segment is one and the marginal cost is zero.

1. A combination of an advance price of $\$ 25$ and a spot price of $\$ 50$ earns $\$ 25+(.1 \times \$ 50)=\$ 30$.

2. Advance selling only, at the best advance price of $\$ 14$, earns $\$ 14 \times 2=\$ 28$, with both segments buying.

3. Advance selling only, at $\$ 26$ (i.e., the best advance price greater than $\$ 14$ ), earns $\$ 26$, with only one segment buying.

4. Only spot selling at a price of $\$ 50$ earns $(.1 \times \$ 50)$ $+(.4 \times \$ 50)=\$ 25$.

Note that the car rental company earns greater profits with a combination of an advance price of $\$ 25$ and a spot price of $\$ 50$ than having either a spot or advance price alone. This is true despite the fact that the car rental company earns no profits when either segment buys their gasoline from an alternative source and the fact that the $\$ 25$ is not the optimal advance price. We now explore the generality of this result given optimal pricing.

\section{Heterogeneous Expectations: The Two-Segment Case}

This section examines a market of size $M$ with two equal-size segments. The first segment is relatively disposed toward a favorable consumption state, whereas the second segment is disposed toward an unfavorable state.

Consider the example of the county fair. Some buyers may have a predisposition to enjoy county fairs and have more consumption states associated with a high utility for a county fair than another segment. The first segment of buyers, for example, may rarely tire of outdoor fair activities. The second segment, in contrast, may tend to grow weary of outdoor activities on consecutive days and be less disposed to enjoy the fair.

Let $q_{H}$ denote the probability of a favorable consumption state for the first segment, which has a higher probability of a favorable consumption state. Let $q_{l}$ denote the probability of a favorable consumption state for the second segment, which has a lower probability of a favorable consumption state. Of course, $q_{L}$ is less than $q_{H}$. Also, let $E R P_{H}$ 
TABLE 2

Profits for Nine Pricing Strategies: Two-Segment Market

\begin{tabular}{llll}
\hline \multirow{2}{*}{$\begin{array}{l}\text { Advance } \\
\text { Purchase Price }\end{array}$} & \multicolumn{3}{c}{ Spot Price } \\
\cline { 2 - 4 } & \multicolumn{1}{c}{ None } & $p_{U}$ & $p_{F}$ \\
\hline None & 0 & $\Pi_{U}$ & $\Pi_{F}$ \\
$E R P_{L}$ & $\Pi_{L}$ & $\Pi_{U}$ & $\Pi_{L}$ \\
$E R P_{H}$ & $\Pi_{H}$ & $\Pi_{U}$ & $\Pi_{C}$ \\
Comparisons & & & \\
When $C<p_{U}$ & $\Pi_{H}<\Pi_{C}$ & $\Pi_{U}<\Pi_{L}$ & $\Pi_{C}>\Pi_{F}$ \\
When $\left(1-q_{\nu}\left(p_{U}-C\right)\right.$ & & & \\
$<\left(q_{H}-q_{L}\right)\left(p_{F}-p_{U}\right)$ & $\Pi_{C}>\Pi_{L}$ & & \\
Otherwise & $\Pi_{C} \leq \Pi_{L}$ & & \\
\hline
\end{tabular}

represent the expected reservation price of the highprobability segment, that is, $E R P_{H}=q_{H} p_{F}+\left(1-q_{H}\right) p_{U}$, and let $E R P_{L}$ represent the expected reservation price of the low-probability segment, such as, $E R P_{L}=q_{L} p_{F}+(1-$ $\left.q_{L}\right) p_{U}$. Here, of course, $E R P_{H}>E R P_{L}$.

As the seller, we might want to use advance pricing following Theorem 1. In that case, we want to sell to the first segment at the high expected reservation price of $E R P_{H}$ and the second segment at their low expected reservation price $E R P_{L}$. However, implementation is difficult because we may be unable to distinguish between the two segments, or, having identified customers by segment, we may find it difficult to charge them different prices. Highprobability customers, for example, may look like lowprobability customers. Moreover, although senior citizens may be disposed toward favorable states, for example, it may be difficult to charge them a higher price.

Given the inability to charge different segments different prices at the same time, the service provider is left with three pricing strategies: no spot price, a favorable reservation spot price, and an unfavorable reservation spot price. There are also three possible advance-pricing strategies: no advance price, a low expected reservation price, and a high expected reservation price. Table 2 provides the profits for each combination, that is, the nine strategies.

Table 2 assumes that when announced spot prices are lower than forward prices, buyers will wait and spot buy. Table 2 also assumes (as noted earlier) the firm honors announced prices. For further discussion, see Shugan and Xie (1997). Finally, Table 2 adopts the standard convention that indifferent buyers will forward buy. Otherwise, we reduce forward prices by an infinitesimally small epsilon.

Let us consider each of the nine strategies in Table 2. Table 2 reveals that many of those strategies produce the same profits. When we, as the service provider, offer a low spot price of $p_{U}$, all buyers prefer to wait, and so our advance price is irrelevant. When we offer a low advance price of $E R P_{L}$, all buyers advance buy so we get the same profits regardless of whether we offer spot sales.
Table 2 also reveals that some strategies are always inferior. When our costs are less than the buyer's reservation price in an unfavorable consumption state, that is, $C<p_{v}$, strategies allowing advance purchase are more profitable than strategies with spot sales alone. Of all strategies, only two strategies yield optimal profits. Theorem 3 and Lemma 3 examine these strategies.

Theorem 3: Only two pricing strategies can produce maximum profits. They are the following:

1. A combination of an advance price that induces the favorably disposed segment to buy, that is, $E R P_{H}$, and a spot price that induces purchases by the unfavorably disposed segment who are in a favorable state, that is, $p_{F}$

2. A pure advance-pricing strategy that prices so that both segments advance purchase, that is, $E R P_{L}$.

Strategy 1 is best when $\left(1-q_{L}\right)\left(p_{U}-C\right)<\left(q_{H}-q_{L}\right)\left(p_{F}-p_{U}\right)$. Strategy 2 is best otherwise.

Lemma 3: The relative profitability of Strategy 1 over Strategy 2 increases with increases in $q_{k}, p_{F}$ and $C$, and decreases in $p_{U}$. The effect of $q_{L}$ on the optimal strategy is moderated by $\Delta=\left(p_{U}-C\right)-\left(p_{F}-p_{U}\right)$.

Theorem 3 says that not only pure advance pricing provides improved profits over spot pricing but also that combination strategies can be profitable. The theorem also provides explicit conditions for each.

The first potentially desirable strategy, in the theorem, is a combination strategy. We offer an advance price that induces the first (favorably disposed) segment to buy, that is, $E R P_{H}$. At the gate, we charge the spot price to customers in the second segment who are in a favorable state, that is, $p_{F}$

The other potentially desirable strategy is a pure strategy. It sets an advance price that induces both segments to advance buy, that is, $E R P_{L}$. At that price, both segments buy and pay a price higher than the spot price that would encourage both segments to buy, that is, $p_{U}$.

Note that the best strategy depends on the sign of $\left(1-q_{D}\right)$ $\left(p_{U}-C\right)-\left(q_{H}-q_{\nu}\right)\left(p_{F}-p_{U}\right)$. The first term, that is, $\left(1-q_{\nu}\right)$ $\left(p_{U}-C\right)$, represents the expected advantage of the pure over the combination strategy. The pure strategy generates more ticket sales than the combination strategy, because it advance sells tickets to unfavorably disposed buyers who would not have purchased spot (being in unfavorable consumption state). The probability of that event is $(1-q \nu$ and the gain is $\left(p_{U}-C\right)$. Hence, the pure strategy provides a relative expected gain of $\left(1-q_{L}\right)\left(p_{v}-C\right)$. This is the expected advantage from advance selling to the second (unfavorably disposed) segment who are in an unfavorable state.

The second term represents the relative expected advantage from a combination strategy over a pure advance- 
selling strategy. The term represents the expected advantage from segmentation. With a combination strategy, it is possible to sell to the two segments at different prices. The second (unfavorably disposed) segment pays a higher price (i.e., $p_{F}$ ) than the first segment (i.e., $E R P_{H}$ ) because only those consumers in a favorable state buy. The expected advantage of segmentation increases as the two segments become more different. The second term, that is, $\left(q_{H}-q_{L}\right)\left(p_{F}-p_{U}\right)$, measures that difference. As the difference in probabilities, that is, $\left(q_{H}-q_{D}\right)$, between the two segments increases, $\left(q_{H}-q_{L}\right)\left(p_{F}-p_{U}\right)$ increases. As the difference in valuations, that is, $\left(p_{F}-p_{U}\right)$, of the segments in the two states increases, $\left(q_{H}-q_{L}\right)\left(p_{F}-p_{U}\right)$ increases.

The relative desirability of the two strategies represents a compromise between the expected advantage of segmentation compared with the expected advantage of advance selling to everyone at the same price. The combination strategy is better when the expected advantage from segmentation is greater, but the pure strategy is better when the expected advantage from advance selling is greater.

An interesting finding in Lemma 3 is that the impact of $q_{L}$ is moderated by $\Delta=\left(p_{U}-C\right)-\left(p_{F}-p_{U}\right)$. The terms $\left(p_{U}-C\right)$ and $\left(p_{F}-p_{U}\right)$ represent the actual gains from advance selling and segmentation, respectively. When the first term is dominant, $\Delta$ is positive, the gain from advance selling to everyone at the same price exceeds the gain from segmentation, and the pure strategy is best. The reverse is true when the segmentation effect dominates.

Increases in the probability $q_{L}$ diminish both effects because the expected gains from advance selling and segmentation are $\left(1-q_{\nu}\right)\left(p_{U}-C\right)$ and $\left(q_{H}-q_{D}\right)\left(p_{F}-p_{U}\right)$, respectively. Because $q_{L}$ has more impact on the dominate effect, the overall effect of $q_{L}$ on the optimal strategies depends on the sign of $\Delta .^{1}$

Finally, the relative profitability of a combination strategy also increases with increases in $q_{H}, p_{F}$, and $C$. Increases in $q_{H}$ and $p_{F}$ increase the expected benefit of segmentation $\left(q_{H}-q_{L}\right)\left(p_{F}-p_{U}\right)$. Increases in $C$ decrease the expected benefit of pure advance selling, that is, $\left(1-q_{L}\right)\left(p_{U}-C\right)$, and thereby increase the relative advantage of the combination strategy.

\section{Comparing Advance Selling With First-Degree Price Discrimination: Two Segments}

With two different segments of customers, the combination of an advance-purchase ticket and a spot ticket fails to provide profits at the level of first-degree price discrimination at the gate. When we offer an advance price of

1. Mathematically, the advantage of a combination strategy over a pure strategy is $\left[\left(q_{u}-p_{u}\right)\left(p_{r}-p_{u}\right)-\left(1-q_{)}\right)\left(p_{u}-C\right)\right]_{2}^{\mu}$, which equals $\left[q_{t} \Delta-\right.$ $\left.p_{v}\left(1+q_{H}\right)+q_{t} p_{r}+C\right) \frac{L}{2}$. Hence, the impact of $q_{L}$ depends on whether $\Delta$ is positive or negative.
$E R P_{L}$, we leave the favorably disposed segment with a surplus of $E R P_{H}-E R P_{L}$. When we offer an advance price of $E R P_{H}$ and a spot price of $p_{F}$ we forego sales to the buyers in the unfavorably disposed segment who find themselves in an unfavorable state, and we lose profits of $\left(1-q_{L}\right)\left(p_{U}-C\right)$ $\mathrm{M} / 2$. Hence, were first-degree price discrimination possible, the service provider would achieve greater profits.

Nevertheless, advance selling produces significantly greater profits than spot prices alone. Moreover, it may be possible to further increase profits by selling tickets in waves. We, for example, could sell tickets 4 weeks, 3 weeks, 2 weeks, and 1 week in advance of the time of consumption. This strategy might produce greater profits when buyer expectations are changing over time.

\section{CONCLUSIONS AND MANAGERIAL IMPLICATIONS}

Understanding the implications of separating purchase and consumption is important because service providers can often create that separation and profit from it. When buyers purchase in advance of consumption, they change their behavior for several reasons. For example, they may be uncertain about their future utilities and, hence, their future valuations of the service. In some consumption states, buyers may have a higher valuation for the service. For example, a bus pass purchased in the morning may have more utility when the afternoon brings a greater need to use the bus.

We discussed the separation of purchase and consumption focusing on advance selling. Some of the many implications for both researchers and managers follow.

- Service providers can create a separation of purchase and consumption by offering advance tickets.

- Service providers can earn more profit by advance selling than only spot pricing at the time of consumption. In fact, in the special case in which buyers are homogeneous in the advance-purchase period (but not the consumption period), advance pricing can provide profits equal to the profits from firstdegree price discrimination in the consumption period. It is possible to show that advance selling usually causes no loss in consumer welfare because advance sales partially occur to customers who would otherwise not purchase. Surplus, however, is often shifted from some customers to others (Shugan and Xie 1997).

- Service providers have an advantage when advance selling because the relative uncertainty of the seller to the buyer, about the buyer's consumption state, increases as the time of consumption approaches. Well before consumption, both buyers and sellers have nearly the same degree of uncertainty. As the consumption period approaches, buyers gain more in- 
formation than sellers do about buyer consumption states. Hence, service providers have a relative advantage selling in the advance purchase period. When service providers sell advance tickets, they transact with customers who are uncertain about their future consumption states. Selling in this forward period puts the service provider in a better position than during the consumption period when buyers know their consumption states.

- Service providers can influence buyers' uncertainty by determining the duration of the advancepurchase period (i.e., the time between the ticket sale and the time when ticket is valid).

- Service providers can influence buyer uncertainty about the valuation of the service in the consumption period by varying the duration of the consumption period (i.e., the period of time for which the ticket is valid). Buyer uncertainty decreases with a longer consumption period because buyers have more ability to control when consumption occurs. Buyers will choose to consume in a more favorable state.

- Although service providers may discount early purchases, they can sell to a much larger number of customers in the advance-purchase period at their expected reservation price $(E R P)$. The number of customers who will buy at $E R P$ is larger than the number who will buy at the same price in the consumption period. Hence, although the advance ticket may be discounted, the larger unit sales often offset the advance-purchase discounts.

- Service providers can use advance selling to segment the market when buyers are heterogeneous. Service providers can combine advance pricing with segmentation by offering a spot price higher than the discounted advance price. This strategy generates more profits than spot pricing alone.

- With buyer heterogeneity, offering both advance and spot sales allows price discrimination but may constrain the range of advance prices. Service providers must compromise between the profits from advance selling to everyone at the same price and the profits from segmentation. Combination strategies are better than pure (advance-only) pricing strategies when buyer heterogeneity is extreme and marginal costs are high.

- A combination strategy of advance and spot tickets requires lower prices for advance tickets; otherwise, consumers will wait to buy. However, when offering only advance tickets, the situation is different. Service providers could offer advance tickets at a higher price than the price at which spot tickets would have been sold. When announcing either a pure advanceticket strategy or a high spot-price strategy, buyers must believe that the service provider will not later turn around and offer a low spot price. Different factors can ensure that seller announcements are credible. For example, a reputation for honesty is essential to business survival (e.g., most profits are from repeat business). Also, each day, a service pro- vider might sell both spot for today and advance for a future date (e.g., passage on a boat), so buyers can observe both prices each day. Finally, if the profits from a high spot price exceed those from a low spot price, the seller will commit to a high spot price.

- Service providers can help consumers overcome some of their uncertainty resulting from early purchasing. For example, service providers may offer more flexibility and a desire for a longer consumption period (i.e., more time to decide when to consume).

The ideas presented in this article might benefit service providers who previously lacked the technological capability of offering multiple prices but may soon be able to do so. Rapid advances in information technology allow more sellers to design forward-selling systems because they can better estimate forward demand with accurate buyer data and analysis. Technological advances (e.g., computerized transaction systems and Internet interfaces) may also soon lower administrative costs and make advance selling more profitable.

Understanding the separation of purchase and consumption provides many interesting research issues. This article suggests several marking implications of this separation and explores one-advance pricing -in detail. Future research could further examine other issues related to the separation and empirically test the impact of the separation on consumer behaviors. Future research could also more fully explore other factors that affect advance selling including capacity constraints, refunds, and other distributions of consumer preferences.

\section{APPENDIX}

\section{Proofs of Theorems}

\section{Proof of Theorem 1}

Let the profits for the three pure strategies be $\pi_{E R P}$ for advance pricing and $\pi_{P U}$ and $\pi_{P F}$ for the two spot-pricing strategies. When $C<p_{U}$, the advance-pricing strategy is the best because

$$
\begin{gathered}
\pi_{E R P}-\pi_{r v}=(E R P-C) M-\left(p_{v}-C\right) M=q\left(p_{r}-p_{U}\right) M>0 . \\
\pi_{\text {ERP }}-\pi_{P f}=(E R P-C) M-q\left(p_{F}-C\right) M=(1-q)\left(p_{v}-C\right) M>0 .
\end{gathered}
$$

The difference of the two spot-pricing strategies is

$$
\begin{gathered}
\pi_{P F}-\pi_{P U}=q\left(p_{F}-C\right) M-\left(p_{U}-C\right) M . \\
\text { If } q>\frac{p_{U}-C}{p_{F}-C} M, \pi_{P F}>\pi_{p U}
\end{gathered}
$$

Profits from the two combination strategies are equivalent to either pure advance or pure spot pricing. For example, selling advance tickets at $E R P$ and spot tickets at $p_{U}$ is equivalent to selling spot tickets at $p_{U}$ only, because all buyers will spot buy. 


\section{Proof of Theorem 2}

Future evaluations are uniformly distributed between $a$ and $b$. For a spot-only strategy, profits are

$$
\Pi=\left(p_{s}-C\right) \frac{b-P_{s}}{b-a} M \text {. }
$$

The best advance price (only) and spot price (only) are

$$
p_{a}^{*}=\frac{a+b}{2} \text { and } p_{s}^{*}=\frac{b+C}{2} \text {. }
$$

respectively, with $C<b$. The difference in profits between an advance-pricing strategy and a spot-pricing strategy is

$$
\Delta \Pi=\Pi_{c}-\Pi_{i}=\left(\frac{a+b}{2}-C\right) M-\left(\frac{b+C}{2}-C\right) M \int_{p i}^{b} f(u) d u \text {. }
$$

Note that $\int_{p_{i}^{*}}^{b} f(u) d u \leq 1$. If $C<a, \Delta \Pi>0$.

\section{Proof of Theorem 3}

The profits of the two advance-pricing strategies are

$$
\Pi_{H}=\left(E R P_{H}-C\right) \frac{M}{2} \text { and } \Pi_{L}=\left(E R P_{L}-C\right) M .
$$

The profits of the two spot-pricing strategies are

$$
\Pi_{v}=\left(p_{u}-C\right) M \text { and } \Pi_{F}=\left(q_{H}+q_{\nu}\right)\left(p_{F}-C\right) \frac{M}{2}
$$

The only effective combination strategy is selling advance tickets at $E R P_{H}$ and spot tickets at $p_{P}$ which yields profits

$$
\Pi_{c}=\Pi_{H}+q_{L}\left(p_{F}-C\right) \frac{M}{2} .
$$

All other combination strategies are equivalent to either pure advance pricing or pure spot pricing. For example, selling advance tickets at $E R P_{H}$ and spot tickets at $p_{U}$ is equivalent to selling spot tickets at $p_{U}$ only.

Now, assume that $C<p_{U}$. We have

$$
\begin{gathered}
\Pi_{v}-\Pi_{L}=-q_{L}\left(p_{F}-p_{U}\right) M<0, \\
\Pi_{H}-\Pi c=-\left[q_{L}\left(p_{F}-C\right)\right] \frac{M}{2}<0, \Pi c-\Pi_{F}=\left(1-q_{H}\right) \frac{\Pi_{U}}{2}>0, \text { and } \\
\Pi c-\Pi_{L}=\left[-\left(1-q_{\nu}\right)\left(p_{U}-C\right)+\left(q_{H}-q_{\nu}\right)\left(p_{F}-p_{U}\right)\right] \frac{M}{2} \\
\text { If }\left(q_{H}-q_{\nu}\right)\left(p_{F}-p_{U}\right)>\left(1-q_{\nu}\right)\left(p_{U}-C\right), \Pi c-\Pi_{L}>0 .
\end{gathered}
$$

Thus, the theorem follows.

The advantage of a combination strategy over a pure advance-pricing strategy can be expressed as

$$
\Pi c-\Pi_{L}=\left[q_{L} \Delta-p_{u}\left(1+q_{H}\right)+q_{A} p_{r}+C\right] \frac{M}{2},
$$

where $\Delta=\left(p_{U}-C\right)-\left(p_{F}-p_{U}\right)$.

Thus, Lemma 3 follows.

\section{REFERENCES}

Ben-Akiva, Moshe and Steven R. Lerman (1985), "Discrete Choice Analysis: Theory and Application to Travel Demand," in MIT Press Series in Transportation Studies, M. L. Manheim, ed. Cambridge, MA: MIT Press.

Bettrnan, James R. (1970), "Information Processing Models of Consumer Behavior," Joumal of Marketing Research, 7 (August), 370-76.

Blattberg, Robert C., Gary Eppen, and Joshua Lieberman (1981), "A Theoretical and Empirical Evaluation of Price Deals for Consurner Noo-durables," Journal of Marketing, 45 (1), 116-29.

Brennan, Michael J. (1979), The Pricing of Contingent Claims in Discrete Time Models," Journal of Finance, 34 (March), 53-68.

Bucklin, Randolph E., Sunil Gupta, and S. Siddarth (1998), "Determining Segmentation in Sales Response across Consumer Purchase Behaviors," Journal of Marketing Research, 35 (May), 189-97.

Cook. Philip J. and Daniel A. Graham (1977), "The Demand for Insurance and Protection: The Case of Irreplaceable Commodities," Quarterty Journal of Economics, 91 (February), 143-54.

Dana, James D. (1998), “Advance-Purchase Discounts and Price Discrimination in Competitive Markets," Journal of Political Economy, $106(2), 395-422$.

Desiraju, Ramarao and Steven Shugan (1998), "Strategic Service Pricing and Yield Management," Jourmal of Marketing, 63 (1), 44.

Fishburn, P. C. (1974), "On the Foundations of Decision Making under Uncertainty," in Essays on Economic Behavior under Uncertainty, M. Balch, D. McFadden, and Wu, eds. Amsterdam, the Netherlands: North Holland.

Gale, $L$ and T. Holmes (1993), "Advance-Purchase Discounts and Monopoly Allocation of Capacity," American Economic Review, 83 (1), $135-46$.

Gibbs, Brian (1993), "Bidirectional Decision Making: Tractable Taste and the Self-Manipulation of Consumption Utility," working paper, Graduate School of Business, Stanford University, Stanford, CA.

Guadagni, Peter M. and John D. C. Little (1983), "A Logit Model of Brand Choice Calibrated on Scanner Data," Marketing Science, 2 (3), 203-38.

Hauser, John R. and Glen L. Urban (1979), “Direct Assessment of Consumer Utility Functions: Von Neumann-Morgenstern Theory Applied to Marketing," Journal of Consumer Research, 5 (March). 251-62.

- and Birger Wernerfelt (1990), "An Evaluation Cost Model of Consideration Sets," Joumal of Consumer Research, 16 (4), 393-408.

Kahn, Barbara E. and Donald R. Lehmann (1991), "Modeling Choice among Assortments," Joumal of Retailing, 67 (Fall), 274-99.

Kreps, David M. (1979), "A Representation Theorem for Preference for Flexibility" Econometrica, 47. (3), 565-77.

Lewis, Tracy R. and David E. M. Sappington (1994), "Supplying Information to Facilitate Price Discrimination," International Economic Review, 35 (2), 309-27.

McFadden, Daniel (1973), "Conditional Logit Analysis of Qualitative Choice Behavior," in Frontiers in Econometrics, P. Zarembka, ed. New York: Academy Press, 105-42.

Metrers, Richard and Vicente Vargas (1999), "Yield Management for the Nonprofit Sector," Journal of Services Research, 1 (3), 215-26.

Moorthy, K. Sridhar and I.P.L. Png (1992), "Market Segmentation, Cannibalization and the Timing of Product Introductions," Management Science, 38 (3). 345-59. 
Padmanabhan, V., Surendra Rajiv, and Kannan Srinivasan (1997), “New Products, Upgrades, and New Releases: A Rationale for Sequential Product Introduction," Joumal of Marketing Research, 34 (Fall), 456.

Plummer, M. L., and R. C. Hartman (1986), “Option Value: A General Approach," Economic Inquiry, 24 (October), 455-72.

Png, I.P.L. (1989), "Reservations: Customer Insurance in the Marketing of Capacity," Marketing Science, 8 (3), 248.

Roberts, John H. and James M. Lattin (1991), “Development and Texting of a Model of Consideration Set Composition," Journal of Marketing Research, 28 (November), 429-40.

Rust, Roland T. and Richard L. Oliver (1994), "Service Quality: Insights and Managerial Implications from the Frontier," in Service Quality: New Directions in Theory and Practice, Roland T. Rust and Richard L. Oliver, eds. Thousand Oaks, CA: Sage, 1-19.

Shugan, Steven M. (1994), "Explanations for Service Growth," in Service Quality, Richard Oliver and Roland Rust, eds. Newbury Park, CA: Sage.

and Jinhong Xie (1997), "Forward Selling Strategies," working paper, University of Florida.

- and - (1999), "Forward Pricing," presented at the 1999 Marketing Science Conference, University of Syracuse, Syracuse, NY, May 21-23.

Wernerfelt, Birger (1995), "A Rational Reconstruction of the Compromise Effect: Using Market Data to Infer Utilities," Journal of Consumer Research, 4 (March), 627-33.

Xie, Jinhong and Marvin A. Sirbu (1995), "Price Competition and Compatibility in the Presence of Network Externalities," Management Science, 41 (May), 909-26.

Steven M. Shugan is the Russell Berrie Foundation Eminent Scholar and Professor of Marketing at the University of Florida Warrington School of Business. He received his Ph.D. in managerial economics and decision sciences from Northwestern University (1974-1977). He has taught at Northwestern University (1975-1977), the University of Rochester (1977-1979), the University of Chicago (1979-1992), and the University of Florida (1992-present). He serves on the editorial boards of the Journal of Marketing Research, Journal of Marketing, Journal of Services Research, and Marketing Science. His research interests include competitive models, services marketing, product and service strategy, and entertainment marketing. He has consulted for numerous companies in the business service and health care sector as well as the U.S. Postal Service and the Government of Cyprus. His recent publications include "Strategic Service Pricing and Yield Management" (with R. Desiraju), Journal of Marketing (January 1999); "Seasonal Marketing and Timing New Product Introductions" (with S. Radas), Joumal of Marketing Research (August 1998); and "Managing Service Demand: Shifting and Bundling" (with S. Radas), Joumal of Service Research (August 1998). He has won several awards including the University of Florida Teaching Award (TIP) and appointment as the university research foundation professor.

Jinhong Xie is an assistant professor of marketing in the College of Business Administration at the University of Florida. She received her B.S. in electrical engineering from Tsinghua University (China), her M.S. in optimal control from the Second Academy of the Ministry of Astronautics (China), and her M.S. and Ph.D. in engineering and public policy from Carnegie Mellon University. She has taught at the University of Rochester and the University of Florida. Her research interests include service pricing, new product development, diffusion and forecasting, market entry strategy, cross-functional integration in new product development, and national culture effects on cross-functional interface management. She has conducted research on companies in East Asia, Europe, and the United States. Her recent publications include "Antecedents and Consequences of Marketing Managers' Conflict Handling Behaviors" (with M. Song and B. Dyer), Joumal of Marketing (forthcoming 2000); "Interfunctional Conflict, Conflict Resolution Styles, and New Product Success: A Four-Culture Comparison" (with M. Song and A. Stringfellow), Management Science (1998); and "Patterns of Cross-Functional Joint Involvement Across Product Development Stages: An Exploratory Study" (with M. Song and J. Thieme), Joumal of Product Innovation Management (1998). She is a recipient of the 1998 University of Florida Teaching Award and the 1992 Marketing Science Institute Research Competition Award. 